\title{
Pathotypes and Genetic Relationship of Worldwide Collections of Elsinö̈ spp. Causing Scab Diseases of Citrus
}

\author{
J. W. Hyun, S. H. Yi, S. J. MacKenzie, L. W. Timmer, K. S. Kim, S. K. Kang, H. M. Kwon, and H. C. Lim
}

First, fifth, and seventh authors: Citrus Experiment Station, National Institute of Subtropical Agriculture, R.D.A. Jeju, 697-943, S. Korea; second author: National Instrumentation Center for Environmental Management (NICEM), Seoul National University, Seoul, 151-921, S. Korea; third author: University of Florida, Gulf Coast Research and Education Center, Wimauma 33598; fourth author, University of Florida, Citrus Research and Education Center, Lake Alfred 33850; sixth author: Korea National Agricultural College, R.D.A., Kyonggido, 445-893, S. Korea; eighth author: Subtropical Environment Division, National Institute of Subtropical Agriculture, R.D.A., Jeju, 690150, S. Korea.

Accepted for publication 17 February 2009.

\begin{abstract}
Hyun, J. W., Yi, S. H., MacKenzie, S. J., Timmer, L. W., Kim, K. S., Kang, S. K., Kwon, H. M., and Lim, H. C. 2009. Pathotypes and genetic relationship of worldwide collections of Elsinö̈ spp. causing scab diseases of citrus. Phytopathology 99:721-728.

Two scab diseases are recognized currently on citrus: citrus scab, caused by Elsinoë fawcettii, and sweet orange scab, caused by E. australis. Because the two species cannot be reliably distinguished by morphological or cultural characteristics, host range and molecular methods must be used to identify isolates. Four pathotypes of E. fawcettii and two of $E$. australis have been described to date based on host range. The host specificity and genetic relationships among 76 isolates from Argentina, Australia, Brazil, Korea, New Zealand, and the United States were investigated. Based on pathogenicity tests on eight differential hosts, 61 isolates were identified as E. fawcettii and 15 as E. australis. Of 61 isolates of E. fawcettii, 24 isolates were identified as the Florida broad host range (FBHR) pathotype, 7 as the Florida narrow host range (FNHR) pathotype, 10 as the Tryon's pathotype, and 3 as the "Lemon" pathotype. Two new pathotypes, the "Jingeul" and the satsuma, rough lemon, grapefruit, clementine (SRGC), are described, and four isolates did not fit into

any of the known pathotypes of E. fawcettii. Of the 15 isolates of $E$. australis from Argentina and Brazil, 9 belonged to the sweet orange pathotype and 6 from Korea to the natsudaidai pathotype. E. fawcettii and E. australis were clearly distinguishable among groups by random amplified polymorphic DNA-polymerase chain reaction (RAPD-PCR) assays and the E. fawcettii group was divided into three subgroups, A-1, A-2, and A-3. The A-1 group was composed of the FBHR, FNHR, and SRGC pathotypes; some Lemon pathotypes; and the uncertain isolates. The A-2 subgroup included all of the Tryon's pathotype isolates and one of the three Lemon pathotype isolates and the A-3 group contained the Jingeul pathotype isolates. E. australis was differentiated into two groups: B-1, the natsudaidai pathotype isolates, and B-2, the sweet orange pathotype isolates. Isolates of E. fawcettii and E. australis were clearly distinguishable by sequence analysis of the internal transcribed spacer (ITS) region and the translation elongation factor $1 \alpha$ (TEF) gene. There were also fixed nucleotide differences in the ITS and TEF genes that distinguished subgroups separated by RAPD-PCR within species. We confirmed two species of Elsinoë, two pathotypes of E. australis, and at least six pathotypes of E. fawcettii and described their distribution in the countries included in this study.
\end{abstract}

Citrus scab diseases cause fruit blemishes that reduce the value of fruit for the fresh market and are important wherever susceptible cultivars are grown for fresh fruit in humid areas. Depending on the species or pathotype of scab involved, this disease may affect commercial species of citrus such as sweet orange (Citrus sinensis), lemon (C. limon), grapefruit (C. paradisi), many tangerine and mandarin lines ( $C$. reticulata), satsuma mandarin $(C$. unshiu), clementine ( $C$. clementina), and their hybrids, as well as species used for rootstocks such as sour orange (C. aurantium), rough lemon (C. jambhiri), and cleopatra mandarin $(C$. reshni). Bitancourt and Jenkins $(2,3)$ and Jenkins (8) differentiated three scab diseases on the basis of morphological and cultural characteristics of the pathogens such as conidial size and colony color: citrus scab, formerly known as sour orange scab, caused by Elsinö̈ fawcettii Bitanc. \& Jenkins (anamorph Spaceloma fawcettii Jenkins) (14); Tryon's scab, caused by $S$. fawcettii Jenkins var. scabiosa (McAlp. \& Tryon) Jenkins $(8,15)$; and sweet orange scab, caused by E. australis Bitanc. \& Jenkins (anamorph S. australis Bitanc. \& Jenkins) (13). Whiteside (18) described two biotypes of E. fawcettii. One affected fruit and

Corresponding author: L. W. Timmer; E-mail address: lwtimmer@ufl.edu

doi:10.1094/PHYTO-99-6-0721

(C) 2009 The American Phytopathological Society leaves of sour orange, Temple tangor $(C$. sinensis $\times C$. reticulata $)$, grapefruit, lemon, and rough lemon and fruit, but not leaves, of sweet orange. The second affected all of the above except sour orange, Temple tangor, and sweet orange fruit. He suggested pathogenicity tests on rough lemon and sour orange seedlings to differentiate the two types. Whiteside (19) also questioned whether the pathogen causing scab of sweet orange fruit, presumably due to E. australis in South America, could be differentiated from the biotype of $E$. fawcettii that affects sweet orange and whether $E$. australis, as described in Brazil $(3,13)$, even constituted a separate taxon. In subsequent work, Timmer et al. (17) and Tan et al. (16) described the strains of citrus scab as pathotypes rather than biotypes and designated Tryon's scab as a pathotype of E. fawcettii and described the "Lemon" pathotype using five differential hosts: rough lemon, cleopatra mandarin, Rangpur (C. limonia), sour orange, and grapefruit. Timmer et al. (17) reported that species of Elsinoë were very difficult to distinguish by conidial size and shape and colony color but could be differentiated reliably by pathogenicity. Tan et al. (16) readily differentiated E. australis from the Florida and Australian pathotypes of $E$. fawcettii by restriction analysis of the amplified internal transcribed spacer (ITS) of ribosomal DNA (rDNA) using several endonucleases, by sequencing of the ITS region, and by random amplified polymorphic DNA (RAPD) analyses. Hyun et al. (7) reported a new pathotype of E. australis from fruit of 
natsudaidai in Korea. This pathotype did not infect leaves of any citrus species tested and was pathogenic only to natsudaidai fruit and appeared to be closely related to E. australis by molecular analysis. Hyun et al. (6) developed a polymerase chain reaction (PCR) method for the identification of species and the two pathotypes of E. australis using SCAR markers and by the ITS sequence.

The objectives of this study were to determine whether new pathotypes of E. fawcettii or E. australis existed by inoculation of additional host species, ascertain whether the pathotypes could be distinguished using RAPD analysis and sequencing of the ITS region and a segment of the translation elongation factor $1 \alpha$ gene (TEF), and determine the relationship among pathotypes and isolates of these pathogens from different geographical areas.

\section{MATERIALS AND METHODS}

Isolates. Seventy-six isolates of Elsinö spp. from citrus were collected from Argentina, Australia, Brazil, Korea, New Zealand, and the United States (Table 1). Isolates from Jeju Island, Korea were recovered from leaves or fruit of five citrus species (Table
1). Isolations were made by disinfesting fruit or leaves for $1 \mathrm{~min}$ in $75 \%$ ethanol and then $1 \mathrm{~min}$ in $1 \%$ sodium hypochlorite followed by rinsing in sterile water. After drying, scab pustules were scraped with a scalpel to deposit flakes of diseased tissue onto half-strength potato dextrose agar (PDA) (12.0 g of potato dextrose broth and $15 \mathrm{~g}$ of agar in 1 liter of distilled water). Isolates from Florida were recovered in a similar manner using the selective medium of Whiteside (16). All other isolates were received from other investigators as described in Table 1.

Pathogenicity. Pathogenicity was determined by inoculating young leaves of rough lemon, grapefruit, sour orange, cleopatra mandarin, satsuma mandarin, Jingeul ( $C$. sunki), and clementine and, in some cases, fruit of natsudaidai and sweet orange. Seedlings of these citrus species were grown in a greenhouse maintained at 18 to $33^{\circ} \mathrm{C}$. Plants were pruned to stimulate production of uniform flushes of new leaves and inoculated when leaves were one-fourth of mature size by spraying with a suspension of $10^{6}$ conidia/ml produced by the method of Whiteside (18). The plants were covered with plastic bags for $48 \mathrm{~h}$ after inoculation and symptom severity was recorded when the leaves were mature. Inoculations with isolates were conducted in blocks over time as

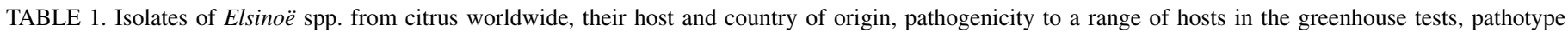
designation, and designations for the sequences of the translation elongation factor $\alpha$ (TEF) and internal transcribed spacer (ITS)

\begin{tabular}{|c|c|c|c|c|c|c|c|c|c|c|c|}
\hline \multirow{2}{*}{$\frac{\text { Isolate }^{\mathrm{a}}}{\text { Location, no, designation }}$} & \multirow[b]{2}{*}{$\operatorname{Host}^{\mathrm{b}}$} & \multicolumn{8}{|c|}{ Pathogenicity $^{\mathrm{c}}$} & \multirow[b]{2}{*}{ Pathotype $^{\mathrm{d}}$} & \multirow[b]{2}{*}{ ITS/TEF genotype } \\
\hline & & SM & RL & $\mathrm{SO}$ & $\mathrm{GF}$ & $\mathrm{CM}$ & $\mathrm{NDF}$ & JIN & Clem & & \\
\hline \multicolumn{12}{|l|}{ Korea (Jeju Island) } \\
\hline 1, SM3-1 & SM & + & + & + & + & + & - & - & $\mathrm{N}$ & FBHR & A-1 \\
\hline 2, SM12-1 & SM & + & + & \pm & + & + & - & - & $\mathrm{N}$ & FNHR & A-1 \\
\hline 3, SM12-2 & SM & + & + & + & + & + & - & - & $\mathrm{N}$ & FBHR & A-1 \\
\hline 4, SM12-5 & SM & + & + & + & + & + & $\mathrm{N}$ & - & $\mathrm{N}$ & FBHR & A-1 \\
\hline 5, SM16-1 & SM & + & + & + & + & + & $\mathrm{N}$ & - & + & FBHR & $A-1$ \\
\hline 6, SM16-3 & SM & + & + & + & + & + & $\mathrm{N}$ & - & $\mathrm{N}$ & FBHR & A-1 \\
\hline 7, SM16-4 & SM & + & + & + & + & + & $\mathrm{N}$ & - & $\mathrm{N}$ & FBHR & A-1 \\
\hline 8, SM16-8 & SM & + & + & \pm & + & + & - & - & $\mathrm{N}$ & FNHR & A-1 \\
\hline 9, SM24-1 & SM & + & + & + & + & + & - & - & + & FBHR & A-1 \\
\hline 10, SM24-4 & SM & + & + & + & + & + & $\mathrm{N}$ & - & $\mathrm{N}$ & FBHR & A-1 \\
\hline 11, MUD & SM & + & + & + & + & + & $\mathrm{N}$ & - & $\mathrm{N}$ & FBHR & A-1 \\
\hline 12, Yuzu1-3 & $\mathrm{YZ}$ & + & + & + & + & + & - & - & \pm & FBHR & A-1 \\
\hline 13, Yuzu2-1 & $\mathrm{YZ}$ & + & + & + & + & + & $\mathrm{N}$ & - & $\mathrm{N}$ & FBHR & A-1 \\
\hline 14, Yuzu2-2 & $\mathrm{YZ}$ & + & + & + & + & + & $\mathrm{N}$ & - & $\mathrm{N}$ & FBHR & A-1 \\
\hline 15, Ryuzu-1 & $\mathrm{YZ}$ & + & + & + & + & + & $\mathrm{N}$ & - & \pm & FBHR & A-1 \\
\hline 16 , Ryuzu-2 & $\mathrm{YZ}$ & + & + & + & + & + & $\mathrm{N}$ & - & + & FBHR & A-1 \\
\hline 17, Ryuzu-3 & $\mathrm{YZ}$ & + & + & + & + & + & $\mathrm{N}$ & - & $\mathrm{N}$ & FBHR & A-1 \\
\hline 18, Maru-1 & KK & + & + & + & + & + & - & $\mathrm{N}$ & \pm & FBHR & A-1 \\
\hline 19, Maru-2 & KK & + & + & + & + & + & $\mathrm{N}$ & $\mathrm{N}$ & \pm & FBHR & A-1 \\
\hline 20, Maru-3 & $\mathrm{KK}$ & + & + & + & + & + & $\mathrm{N}$ & $\mathrm{N}$ & $\bar{N}$ & FBHR & A-1 \\
\hline 21, Maru-5 & KK & + & + & + & + & + & $\mathrm{N}$ & $\mathrm{N}$ & $\mathrm{N}$ & FBHR & A-1 \\
\hline 22, Jin-1 & JIN & - & + & - & - & - & - & + & + & Jingeul & A-3-2 \\
\hline 23 , Jin-2 & JIN & - & + & - & - & \pm & $\mathrm{N}$ & + & + & Jingeul & A-3-2 \\
\hline 24, Jin-3 & JIN & - & + & - & - & - & - & + & + & Jingeul & A-3-2 \\
\hline 25 , Jin- 6 & JIN & - & + & - & - & \pm & $\mathrm{N}$ & + & $\mathrm{N}$ & Jingeul & A-3-1 \\
\hline 26, Jin-7 & JIN & - & + & - & - & \pm & $\mathrm{N}$ & + & $\mathrm{N}$ & Jingeul & A-3-1 \\
\hline 27, Jin- 8 & JIN & - & + & - & - & \pm & $\mathrm{N}$ & + & $\mathrm{N}$ & Jingeul & A-3-2 \\
\hline $28, \mathrm{Na}-1$ & $\mathrm{NDF}$ & - & - & - & - & - & + & - & - & Natsudaidai & B-1-3 \\
\hline $29, \mathrm{Na}-2$ & $\mathrm{NDF}$ & - & - & - & - & - & + & $\mathrm{N}$ & $\mathrm{N}$ & Natsudaidai & B-1-3 \\
\hline $30, \mathrm{KNa}-1$ & $\mathrm{NDF}$ & - & - & - & - & - & + & - & - & Natsudaidai & B-1-2 \\
\hline $31, \mathrm{KNa}-2$ & $\mathrm{NDF}$ & - & - & - & - & - & + & $\mathrm{N}$ & $\mathrm{N}$ & Natsudaidai & B-1-2 \\
\hline $32, \mathrm{KNa}-5$ & $\mathrm{NDF}$ & - & - & - & - & - & + & $\mathrm{N}$ & $\mathrm{N}$ & Natsudaidai & B-1-1 \\
\hline $33, \mathrm{KNa}-9$ & $\mathrm{NDF}$ & - & - & - & - & - & + & $\mathrm{N}$ & $\mathrm{N}$ & Natsudaidai & B-1-2 \\
\hline
\end{tabular}

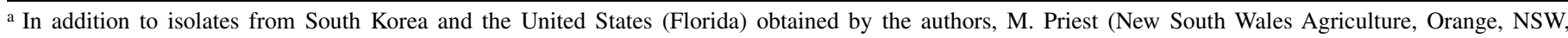
Australia) provided the isolates from Australia (New South Wales) and some of the isolates from Argentina (Entre Rios) from his collection; Sergio M. Garran (EEA, INTA, Concordia, Entre Rios, Argentina) provided most of the isolates from Argentina (Entre Rios); R. A. Fullerton (The Horticulture and Food Research Institute, Auckland, New Zealand) supplied those from New Zealand; and N. A. Peres (Univ. Florida, GCREC, Wimauma, Florida) provided the isolates from Brazil (São Paulo) for this study. All isolates were maintained in silica gel at $-20^{\circ} \mathrm{C}$.

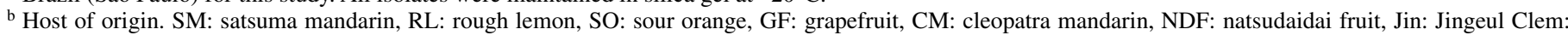
clementine mandarin, SwO: sweet orange, YZ: yuzu (Citrus junos), KK: kinkoji (C. obovoidea), Val: Valencia sweet orange, Emp: Emperor mandarin, Tem: Temple tangor, Carrizo: Carrizo citrange, Volk: Citrus volkameriana, SCSK: Sun chu sha kat mandarin, VFL: Villafranca lemon, YBL: Yen Ben lemon, NZGF: New Zealand grapefruit, ML: Meyer lemon.

c Symbols: $+=$ pathogenic, $-=$ nonpathogenic, $\pm=$ spotting but no clearly identifiable scab lesions, and $\mathrm{N}=$ not tested.

d FBHR: Florida broad host range; FNHR: Florida narrow host range; SRGC: satsuma, rough lemon, grapefruit, clementine. 
plants with susceptible young growth were available, using at least one plant for each isolate and all of the host species. A plant was considered positive for infection if a clearly distinguishable scab lesion developed. Pathogenicity tests on fruit were conducted by spraying the fruit 6 weeks after petal fall with a conidial suspension at $10^{6} / \mathrm{ml}$. In total, 5 to 10 fruit were used for each isolate. Fruit were covered with plastic bags for 7 days after inoculation and symptoms rated 30 days later. Pathogenicity tests were repeated at least three times in all cases and, in some cases, more often when no symptoms were observed. Reisolations were made from symptomatic plants inoculated with some isolates and were conducted if there was any doubt about the identity of the symptoms.

RAPD assays. Total DNA of each fungal isolate was extracted from mycelium grown for 15 days on PDA at $27^{\circ} \mathrm{C}$ using a DNA extraction kit (MO Bio Laboratories Inc., Carlsbad, CA) following the manufacturer's instructions, except that cell wall disruption was by grinding the mycelium to a fine powder after freezing in liquid nitrogen. The extracted DNA was stored at $-70^{\circ} \mathrm{C}$ until used. Total genomic DNA of each fungal isolate was used as a template for amplification with nine random 10-mer primers from
Operon Primer Kit P and X (Operon Technologies, Alameda, CA) previously selected (7) and 10 primers (17 to 20 mer) from the Microbial Universal Primer (MUP) strain-typing kit (Takara Korea Biomedical Inc., Seoul, Korea). Amplification reactions were done in a 20- $\mu$ l reaction mixture of AccuPower PCR PreMix (Bioneer, Seoul, Korea) with 10 pmol each primer and $\approx 5 \mathrm{ng}$ of template DNA. The PCR reaction was performed in a programmable thermocycler (Perkin-Elmer Cetus thermal cycler, model 480), using an initial denaturation step of $95^{\circ} \mathrm{C}$ for $2 \mathrm{~min}$; followed by 40 amplification cycles of denaturation at $94^{\circ} \mathrm{C}$ for $30 \mathrm{~s}$, annealing at $40^{\circ} \mathrm{C}$ for the Operon Primer Kit and $55^{\circ} \mathrm{C}$ for the MUP kit for $1 \mathrm{~min}$, and extension at $72^{\circ} \mathrm{C}$ for $2 \mathrm{~min}$; and a final extension at $72^{\circ} \mathrm{C}$ for $10 \mathrm{~min}$. After PCR, $10 \mu \mathrm{l}$ of the product were electrophoresed in a $1.0 \%$ agarose gel in $1 \times$ Trisacetate EDTA (TAE) and visualized by ethidium bromide staining. Fragments were sized by comparison with a 1-kb DNA ladder (New England Biolabs, Ipswich, MA). RAPD-PCR was conducted two to three times with new preparations of DNA and results were the same each time. Standard isolates (SM 12-1 and 70027) were included in each run and the gel patterns obtained in this study were the same as those observed in a previous study (7)

TABLE 1. (continued from preceding page)

\begin{tabular}{|c|c|c|c|c|c|c|c|c|c|c|c|}
\hline \multirow{2}{*}{$\begin{array}{l}\text { Isolate }^{\mathrm{a}} \\
\text { Location, no, designation }\end{array}$} & \multirow[b]{2}{*}{ Host $^{b}$} & \multicolumn{8}{|c|}{ Pathogenicity ${ }^{\mathrm{c}}$} & \multirow[b]{2}{*}{ Pathotype $^{\mathrm{d}}$} & \multirow[b]{2}{*}{ ITS/TEF genotype } \\
\hline & & SM & RL & $\mathrm{SO}$ & GF & $\mathrm{CM}$ & NDF & JIN & Clem & & \\
\hline \multicolumn{12}{|l|}{ United States (Florida) } \\
\hline $34, \mathrm{Scott}$ & Tem & + & + & - & + & + & $\mathrm{N}$ & $\mathrm{N}$ & $\mathrm{N}$ & FNHR & A-1 \\
\hline 35, S38162 (70254) & GF & + & + & - & + & + & - & - & $\mathrm{N}$ & FNHR & A-1 \\
\hline 36, Volk (70033) & Volk & + & + & - & + & + & $\mathrm{N}$ & $\mathrm{N}$ & + & FNHR & A-1 \\
\hline $37, \mathrm{CC}-1$ & GF & + & + & - & + & + & $\mathrm{N}$ & $\mathrm{N}$ & $\mathrm{N}$ & FNHR & A-1 \\
\hline 38, Smoak-1 & Tem & + & + & + & + & + & $\mathrm{N}$ & $\mathrm{N}$ & $\mathrm{N}$ & FBHR & A-1 \\
\hline 39, SCSK & SCSK & + & + & + & + & + & $\mathrm{N}$ & $\mathrm{N}$ & $\mathrm{N}$ & FBHR & A-1 \\
\hline 40, Russell-15 (70056) & Tem & + & + & + & + & + & $\mathrm{N}$ & $\mathrm{N}$ & $\mathrm{N}$ & FBHR & A-1 \\
\hline 41, Russell-34 & Tem & + & + & + & + & + & - & - & + & FBHR & A. 1 \\
\hline 42, Eus-Mur-3 & Murcott & + & + & - & + & - & - & - & + & SRGC & A-1 \\
\hline 43, Eus-Mur-4 & Murcott & + & + & - & + & - & $\mathrm{N}$ & - & + & SRGC & A-1 \\
\hline $44, \mathrm{CC}-3$ & Tem & - & + & - & - & - & $\mathrm{N}$ & - & - & Lemon & A-1 \\
\hline 45, Carrizo & Carrizo & + & + & + & + & + & $\mathrm{N}$ & + & + & FBHR & A-1 \\
\hline 46, SS-Imk-Lime-1 & Tahiti lime & + & + & - & + & - & $\mathrm{N}$ & - & + & SRGC & A-1 \\
\hline 47, Con-Cal-4 & Calamondin & + & + & + & - & - & $\mathrm{N}$ & - & + & $?$ & A-1 \\
\hline 48, Navarro-1 & $\mathrm{GF}$ & + & + & + & + & - & $\mathrm{N}$ & + & - & $?$ & A-1 \\
\hline \multicolumn{12}{|l|}{ Argentina (Entre Rios) } \\
\hline 49,70041 & Val & - & $\mathrm{N}$ & - & - & - & - & - & $\mathrm{N}$ & Sweet orange & B-2-1 \\
\hline 50,70212 & SM & - & $\mathrm{N}$ & - & - & - & - & - & $\mathrm{N}$ & Sweet orange & B-2-4 \\
\hline $51, \mathrm{Ea}-1$ & SM & - & $\mathrm{N}$ & - & - & - & $\mathrm{N}$ & $\mathrm{N}$ & $\mathrm{N}$ & Sweet orange & B-2-1 \\
\hline $52, \mathrm{Ea}-2$ & Val & - & $\mathrm{N}$ & - & - & - & $\mathrm{N}$ & $\mathrm{N}$ & $\mathrm{N}$ & Sweet orange & B-2-1 \\
\hline $53, \mathrm{Ea}-3$ & Val & - & $\mathrm{N}$ & - & - & - & $\mathrm{N}$ & $\mathrm{N}$ & $\mathrm{N}$ & Sweet orange & B-2-1 \\
\hline $54, \mathrm{Ea}-4$ & SM & - & $\mathrm{N}$ & - & - & - & $\mathrm{N}$ & $\mathrm{N}$ & $\mathrm{N}$ & Sweet orange & B-2-1 \\
\hline \multicolumn{12}{|l|}{ Brazil (São Paulo) } \\
\hline 55, VRG-BRT & SwO & - & $\mathrm{N}$ & - & - & - & $\mathrm{N}$ & - & - & Sweet orange & B-2-3 \\
\hline 56, Fz-STM-CLB-1.4 & $\mathrm{SwO}$ & - & $\mathrm{N}$ & - & - & - & $\mathrm{N}$ & - & - & Sweet orange & B-2-2 \\
\hline 57, Fz-STM-CLB-1.5 & SwO & - & $\mathrm{N}$ & - & - & - & $\mathrm{N}$ & - & - & Sweet orange & B-2-2 \\
\hline 58, VRG-7L-5 & Murcott & + & + & - & - & - & $\mathrm{N}$ & - & + & $?$ & A-1 \\
\hline \multicolumn{12}{|c|}{ Australia (New South Wales) } \\
\hline 59,70027 & Lemon & - & + & - & - & + & $\mathrm{N}$ & - & + & Tryon's & A-2 \\
\hline 60,70187 & Lemon & - & + & - & - & - & $\mathrm{N}$ & - & - & Lemon & A-2 \\
\hline 61,70298 & Emp & - & + & - & - & + & $\mathrm{N}$ & - & + & Tyron's & A-2 \\
\hline 62, DAR 70024 & C. indica & - & + & - & - & + & $\mathrm{N}$ & - & + & Tryon's & A-2 \\
\hline 63, DAR 70025 & Bergamot & - & + & - & - & + & $\mathrm{N}$ & - & + & Tryon's & A-2 \\
\hline 64, DAR 70180 & RL & - & + & - & - & + & $\mathrm{N}$ & - & + & Tryon's & A-2 \\
\hline 65, DAR 70181 & RL & - & + & - & - & + & $\mathrm{N}$ & - & + & Tryon's & A-2 \\
\hline 66, DAR 70184 & RL & - & + & - & - & + & $\mathrm{N}$ & - & + & Tryon's & A-2 \\
\hline \multicolumn{12}{|l|}{ New Zealand } \\
\hline $67, \mathrm{CC}-83$ & VFL & - & + & - & - & + & $\mathrm{N}$ & - & + & Tryon's & A-2 \\
\hline $68, \mathrm{CC}-132$ & YBL & + & + & - & + & - & $\mathrm{N}$ & - & + & SRGC & A-1 \\
\hline $69, \mathrm{CC}-133$ & YBL & + & + & - & - & - & $\mathrm{N}$ & - & - & $?$ & A-1 \\
\hline $70, \mathrm{CC}-134$ & Clem & + & + & - & + & + & $\mathrm{N}$ & - & + & FNHR & A-1 \\
\hline 71, CC-135 & VFL & - & + & - & - & + & $\mathrm{N}$ & - & $\mathrm{N}$ & Tryon's & A-2 \\
\hline $72, \mathrm{CC}-137$ & VFL & - & + & - & - & + & $\mathrm{N}$ & - & - & Tryon's & A-2 \\
\hline $73, \mathrm{CC}-138$ & Clem & + & + & - & + & - & - & - & + & SRGC & A-1 \\
\hline 74, CC-139 & NZGF & + & + & - & + & - & $\mathrm{N}$ & - & + & SRGC & A-1 \\
\hline $75, \mathrm{CC}-140$ & ML & - & + & - & - & - & $\mathrm{N}$ & - & $\mathrm{N}$ & Lemon & A-1 \\
\hline 76, CC-141 & Clem & + & + & - & + & - & $\mathrm{N}$ & - & + & SRGC & A-1 \\
\hline
\end{tabular}


for the isolates (SM12-1, SM 16-8, MUD, Maru-1, Scott, CC-1, Russell-15, 70041, 70212, Ea 1-4, and 70027) that were used in both studies.

Amplification and sequencing of the ITS region and the TEF gene. The rDNA region containing the ITS region was amplified with the primers ITS-4 (5'-TCCTCCGCTTATTGATATGC-3') and ITS-5 (5'-GGAAGTAAAAGTCGTAACAAGG$\left.3^{\prime}\right)$ (1). For sequencing of TEF, a segment was amplified using the primers elongation-1-F (5'-AGCCCCTCCGTCTTCCTCTCCAG$\left.3^{\prime}\right)$ and elongation-1-R (5'-CGGTACGGCGGTCAATCTTCTCG$\left.3^{\prime}\right)$ that were designed for this study based on the partial sequence of E. veneta isolate AFTOL-ID no. 1853, GenBank DQ767641. The amplifications were performed in a programmable thermocycler (Perkin-Elmer Cetus thermal cycler, model 480), using an initial denaturation step of $95^{\circ} \mathrm{C}$ for $2 \mathrm{~min}$; followed by 35 amplification cycles of denaturation at $94^{\circ} \mathrm{C}$ for $30 \mathrm{sec}$, annealing at $55^{\circ} \mathrm{C}$ for the ITS region and $60^{\circ} \mathrm{C}$ for the TEF gene for $1 \mathrm{~min}$, and extension at $72^{\circ} \mathrm{C}$ for $2 \mathrm{~min}$; and a final extension at $72^{\circ} \mathrm{C}$ for $10 \mathrm{~min}$. After PCR, $12 \mu \mathrm{l}$ of the product was electrophoresed in a $1.0 \%$ agarose gel in $1 \times$ TAE buffer for $2 \mathrm{~h}$ at $3 \mathrm{~V} / \mathrm{cm}$ and visualized by ethidium bromide staining. A 500-bp DNA Ladder (GeneRuler, MBI, Fermentas) was used for molecular weight markers.

General procedures for plasmid DNA purification, cloning, and transformation were according to each of the manufacturer's recommendations. The amplified DNA fragments were recovered from agarose gels and purified using the AccuPrep Gel Purification Kit (Bioneer) and then cloned and transformed using the Topo TA Cloning Kit (Invitrogen, Carlsbad, CA). Sequencinggrade plasmid DNA was obtained using the AccuPrep Plasmid Extraction Kit (Bioneer). For each isolate, DNA was sequenced in both directions using M13 forward and SP6 reverse primers for three subclones. Sequencing was done automatically using dyelabeled dideoxy nucleotides and DNA polymerase in an Applied Biosystems 3730XL DNA sequencer (Applied Biosystems, Inc., Foster City, CA). The consensus sequence for the three subclones was used for phylogenetic analysis.

Data analysis. Each RAPD-PCR profile was compared on the basis of the presence versus absence (" 1 " and " 0 ", respectively) of RAPD products of the same electrophoretic mobility. A cluster analysis of Jaccard similarity coefficients was performed with the unweighted pair-group method algorithm using the computer program NTSYS-pc (12). Support values reported for the dendrogram were based on 1,000 bootstrapped samples using Winboot (10). Sequence alignments were done with the program CLUSTAL X 2.0 (9). The sequence used for analysis described as the ITS region consisted of $54 \mathrm{bp}$ of the $18 \mathrm{~S}$ rRNA gene; a region containing the entire ITS1, the 5.8S rRNA gene, and the ITS2; and $58 \mathrm{bp}$ of the $28 \mathrm{~S}$ rRNA gene. The region corresponding to bases 728 to 1,147 of a reference Neurospora TEF gene (GenBank accession no. 45837) was used for phylogenetic analysis. This region consisted entirely of coding sequence and is located within the fourth exon. Maximum parsimony (MP) and neighborjoining $(\mathrm{NJ})$ trees were constructed from the ITS region and TEF separately and with sequence from both regions combined. Prior to combining sequences for tree construction, the incongruencelength difference test was performed to assess the significance of incongruence (4). Incongruence was found not to be significant based on this test $(P=0.19)$. A heuristic search employing 1,000 random stepwise addition replicates and the tree-bisectionreconstruction branch-swapping algorithm was used to find MP trees, and insertions or deletions were treated as a fifth character. Bootstrap values for MP trees were based on 1,000 repetitions. NJ trees used the HKY85 model of sequence evolution (5). This model was chosen because it provided a relatively good fit for the evolution of both sequences and the sequences combined in an analysis using FINDMODEL (Los Alamos National Laboratory, Los Alamos, NM), a web implementation of MODELTEST (11).
All tree construction algorithms and the test for significance of incongruence were run in PAUP 4.0 (Sinaur Associates, Inc., Sunderland, MA). Only midpoint rooted MP trees are reported.

\section{RESULTS}

Pathogenicity and pathotype. In pathogenicity tests with 76 isolates, 61 were determined to be E. fawcettii and 15 to be $E$. australis. Nineteen isolates from satsuma mandarin, yuzu, and kinkoji in Korea and four isolates from Florida were pathogenic to satsuma mandarin, rough lemon, sour orange, grapefruit, and cleopatra mandarin and, thus, were identified as the Florida broad host range (FBHR) pathotype (Table 1). Seven isolates, including two from Korea, four from the United States (Florida), and one from New Zealand, were pathogenic to satsuma mandarin, rough lemon, grapefruit, and cleopatra mandarin only, produced no symptoms on sour orange, and were identified as the Florida narrow host range (FNHR) pathotype. Four isolates from New Zealand and three from Florida resembled the FNHR pathotype in being pathogenic to satsuma mandarin, rough lemon, and grapefruit and not to sour orange but differed in being nonpathogenic to cleopatra mandarin and pathogenic to clementine. Because there were several isolates in this category, we designated this as a new pathotype: satsuma, rough lemon, grapefruit, clementine (SRGC). In all, 7 of 8 isolates from Australia and 3 of 10 isolates from New Zealand were identified as the Tryon's pathotype, because they were pathogenic to rough lemon and cleopatra mandarin but nonpathogenic to satsuma mandarin, sour orange, grapefruit, or Jingeul. However, 8 of the 10 isolates of Tryon's pathotype also proved to be pathogenic to clementine. Three isolates, one each from Australia, New Zealand, and Florida, were only pathogenic to rough lemon and were identified as the Lemon pathotype. Six isolates from Jingeul in Korea were pathogenic to rough lemon, Jingeul, and clementine and were identified as a new pathotype of E. fawcettii which was designated as "Jingeul".

Use of a wider range of hosts also allowed detection of other variants of existing pathotypes. Because these involved mostly single isolates, no new pathotype was designated for these isolates. Some Florida isolates, such as Navarro-1 and Con-Cal-4 that would normally have been categorized as FBHR because they were pathogenic to sour orange, could now be differentiated because Navarro-1 was not pathogenic to cleopatra mandarin but was pathogenic to Jingeul, and Con-Cal-4 was not pathogenic to grapefruit or cleopatra mandarin. The pathogenicity profiles of New Zealand isolates varied considerably, with CC-134 being typical of the FNHR except that it was pathogenic to clementine, and $\mathrm{CC}-133$ being pathogenic only to satsuma mandarin and rough lemon. A Brazilian isolate, VRG-7L-5 from Murcott tangor, was only pathogenic to satsuma mandarin, rough lemon, and clementine.

Nine isolates from sweet orange and satsuma mandarin fruit from Argentina and Brazil were not pathogenic to leaves of any of the cultivars and species tested and, thus, were considered to be the sweet orange pathotype of E. australis. Six isolates from natsudaidai in Korea were only pathogenic to natsudaidai but not to other tested species, including fruit of sweet orange and satsuma mandarin, and were identified as the natsudaidai pathotype of E. australis. A number of isolates of E. fawcettii from Korea, Florida, and New Zealand and two isolates of E. australis from Argentina were tested for pathogenicity on natsudaidai fruit, but none was pathogenic.

RAPD analysis. The 9 random 10 -mer primers and the 10 primers (17 to 20 mer) from the MUP strain-typing kit led to amplification of PCR products, including at least one clear polymorphic product per primer. Primer OPX-17-amplified PCR products showed especially distinct polymorphisms among some pathotypes (Fig. 1). By cluster analysis using all 108 polymorphic fragments, the 76 isolates were divided into two major groups, 
designated $\mathrm{A}$ and $\mathrm{B}$, with a similarity between the two groups of 0.47 (Fig. 2). Group A included isolates of E. fawcettii and group B contained all of the isolates of E. australis. Within group A, subgroup A-1 was composed of all of FNHR, FBHR, SRGC, and unknown pathotype isolates as well as two of three isolates of the Lemon pathotype, one from Florida (CC-3) and one from New Zealand (CC-140). Subgroup A-2 included one isolate of the Lemon pathotype (70187) from Australia and all isolates of Tryon's pathotype. Subgroup A-3 included only the Jingeul pathotype isolates. The similarity values among subgroups A-1, A-2, and A-3 were 0.85 to 0.87 , and the values among isolates within each subgroup were 0.95 to 0.99 . Subgroup B-1 included isolates of the natsudaidai pathotype of E. australis and B-2 included isolates of the sweet orange pathotype of that species. The similarity value between subgroups B-1 and B-2 was $\approx 0.73$.

DNA sequence analyses. The length of the ITS sequence varied from 653 to 654 bp for E. fawcettii and was $626 \mathrm{bp}$ for $E$. australis. The length of the TEF sequence was $420 \mathrm{bp}$ for both species. There was a total of 88 polymorphic sites within the ITS. Of these, 36 were insertions or deletions and 52 were substitutions. There were 34 substitutions in the TEF gene and no insertions or deletions. The MP tree for the ITS region was 89 steps long and the homoplasy index equaled 0.011 (Fig. 3A) and, for the TEF gene, the tree was 34 steps long and the homoplasy index equaled 0 (Fig. 3B). The tree length for both sequences combined was 124 steps and the homoplasy index was 0.016 (Fig. 3C). There was one MP tree for the ITS and TEF sequence data analyzed separately and two when sequence data were combined. When sequences were combined, there were 11 unique genotypes. The genotypes were identified by the RAPD-PCR subgroup designation of isolates, with that genotype followed by a number from one to four if there were multiple ITS or TEF genotypes within a subgroup. For each isolate analyzed, their ITS or TEF genotype is listed in Table 1 and the GenBank numbers for the 11 unique genotypes are reported in Table 2. The two MP trees for the combined data differed with respect to the placement of genotype B-1-1 relative to genotypes B-1-2 and B-1-3.

The ITS region separated isolates from all five RAPD-PCR subgroups identified in Figure 2 (Fig. 3A). There were 83 substitutions, insertions, or deletions fixed in both species that differentiated E. fawcettii isolates from E. australis isolates. Within $E$. fawcettii, all A-2 and A-3 RAPD-PCR subgroup isolates could be differentiated from the A-1 subgroup by the presence of a single insertion. Among isolates from the A-2 and A-3 groups, there was an additional substitution fixed within the A-3 subgroup that distinguished these isolates from all others. Among E. australis isolates, a single unique substitution fixed among B-2 isolates distinguished them from B-1 isolates.

The TEF did not clearly differentiate all five RAPD-PCR subgroups (Fig. 3B). There were 25 nucleotide differences fixed within both species that differentiated $E$. fawcettii isolates from $E$. australis isolates. There was no branch separating A-1 from A-2 isolates. Although there was a branch separating four of the five A-3 isolates from other E. fawcettii isolates, the substitution along this branch was not present in the A-3-1 genotype. Among E. australis isolates, B-1 isolates were more clearly differentiated from B-2 isolates than they were with ITS sequence. There were three substitutions along a branch that differentiated B-1 isolates and one that differentiated B-2 isolates from a common ancestor, resulting in four fixed nucleotide differences between the two subgroups. There were an additional three polymorphic sites within B-2 and one within B-1. Combining sequences did not alter groupings and produced more support for the clade comprising B-2 isolates (Fig. 3C).

In $\mathrm{NJ}$ trees (data not shown), the branch separating A-2 and A-3 isolates from A-1 isolates in the MP tree constructed from ITS and combined data was not present. This was because insertions or deletions are not used to calculate distances required for $\mathrm{NJ}$ tree construction. Also, when compared with MP trees, within the B-2 clade, genotype B-2-4 occupied a different position in the NJ

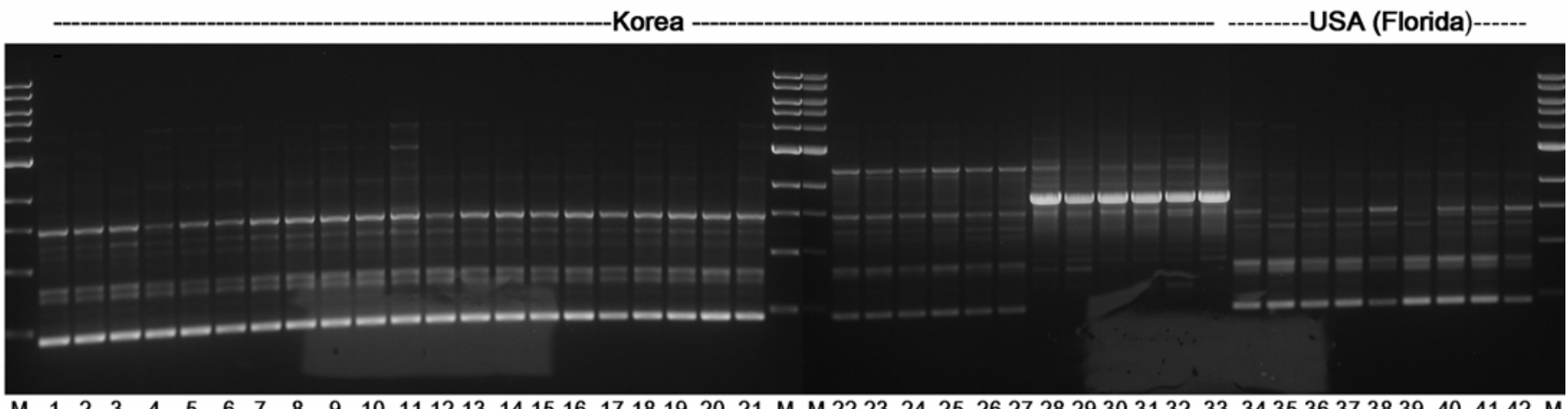

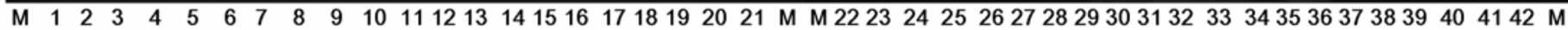

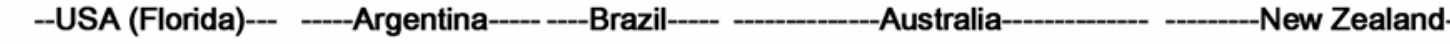

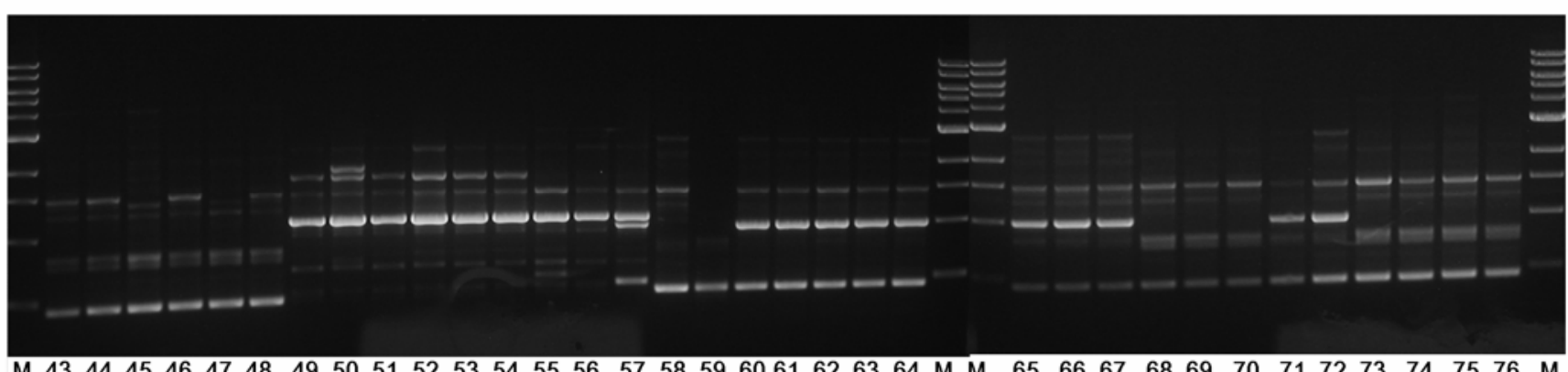

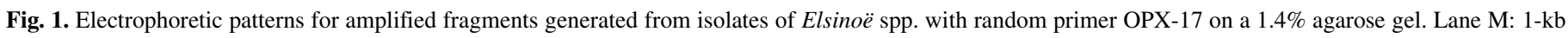
DNA Ladder (New England BioLabs, Ipswich, MA); other lane numbers correspond to the isolate numbers in Table 1. 
tree constructed from the ITS and the combined data. Otherwise, NJ trees were identical to MP trees shown in Figure 3.

\section{DISCUSSION}

In this study, we have greatly expanded our knowledge of the pathotypes of E. fawcettii and E. australis and their distribution in the world. Timmer et al. (17) and Tan et al. (16) described four pathotypes: the FBHR; the FNHR; the Tryon's pathotype, which included most of the former S. fawcettii var. scabiosa isolates (8); and the Lemon pathotype, which was newly described from Australia. By expanding the number of hosts tested, we have discovered at least two new pathotypes, the Jingeul and the SRGC types. In addition, we found single isolates from various areas that

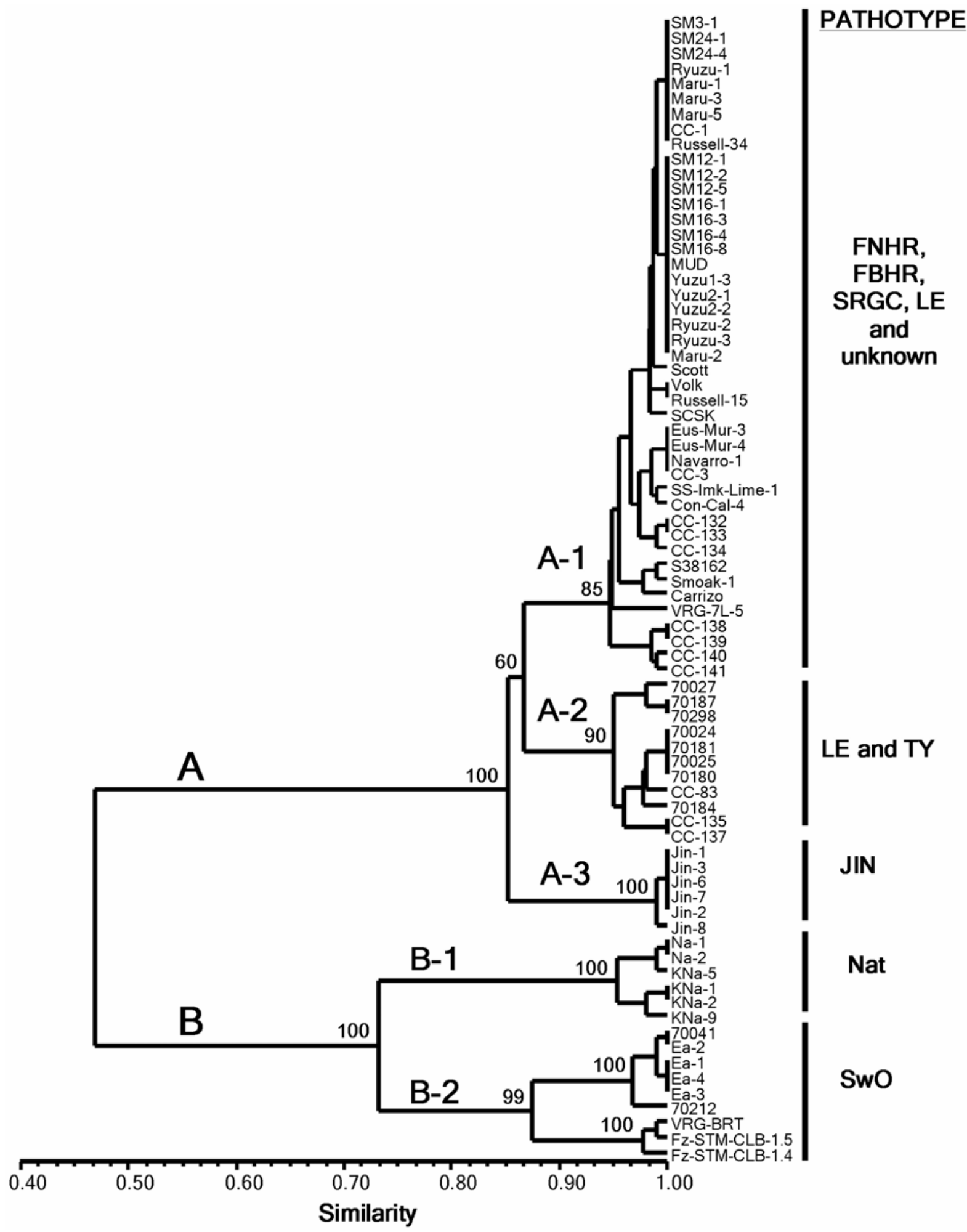

Fig. 2. Dendrogram constructed using the unweighted pair-group method showing the Jaccard similarity of the random amplified polymorphic DNA banding patterns from Elsinoe spp. causing scab on citrus. Florida narrow host range (FNHR), Florida broad host range (FBHR), "Lemon" (LE), Tryon's (TY), and "Jingeul" (JIN) are pathotypes of Elsinoë fawcettii and natsudaidai (Nat) and sweet orange (SwO) are pathotypes of E. australis. SRGC = satsuma, rough lemon, grapefruit, clementine pathotype. Support values at nodes represent the percent occurrence of the cluster to the right of the branch in 1,000 bootstrapped samples. Only values for clusters with $<0.90$ similarity to other isolates or clusters are reported. 
do not correspond to any described pathotype. These isolates probably represent additional new pathotypes of E. fawcettii. We chose not to describe these as new pathotypes at the present time because they are represented mostly by single isolates. Genetic analyses indicated that they fit within the subgroup comprising the majority of the E. fawcettii isolates and do not represent major new subgroups or pathotypes. If additional isolates with these host ranges are found, new pathotypes can be designated at that time. It is highly likely that many additional pathotypes of $E$. fawcettii exist and could be found if more hosts were tested or isolates from other citrus areas of the world were evaluated. FBHR has been confirmed only from Florida and Korea to date but appears to be quite common in those two areas. The FNHR was found among isolates only from Florida, Korea, and New Zealand but the sample size from other areas was small. The Tryon's and Lemon pathotypes are most common in Australia and New Zealand but a single isolate of the Lemon pathotype was found in Florida. The newly described Jingeul pathotype was confirmed only in Korea but the new SRGC pathotype was found in Florida and New Zealand.

There was good agreement among the results of the pathological assays, the RAPD-PCR, and the sequence information from the ITS and the TEF. The two species of Elsino $\ddot{e}$ and two pathotypes of E. australis were separable by pathological assays and by molecular means. Within E. fawcettii, the Jingeul patho-

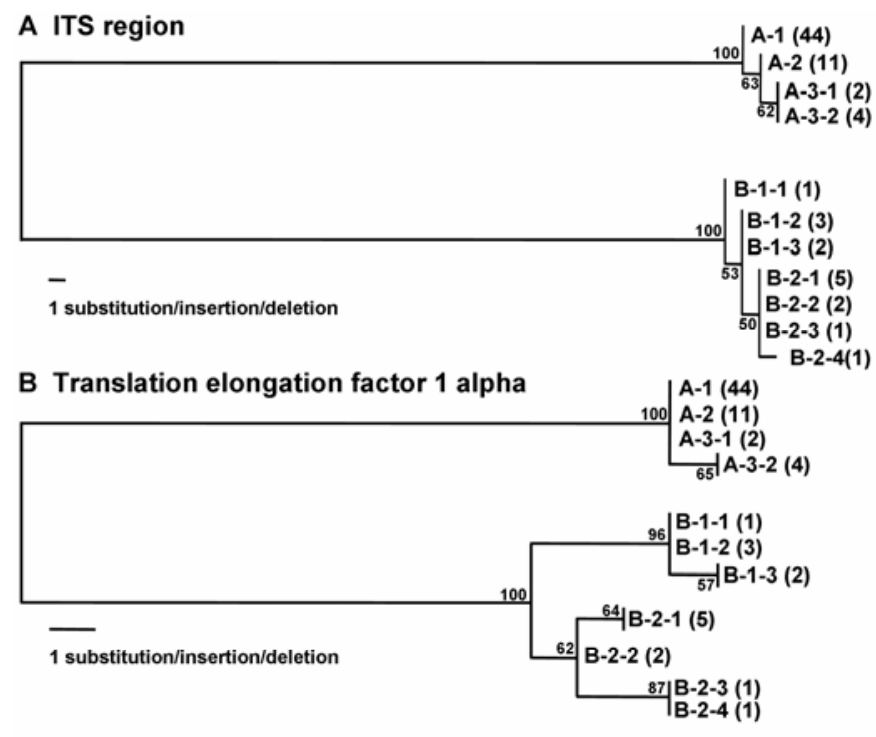

\section{ITS region + Translation elongation factor 1 alpha}

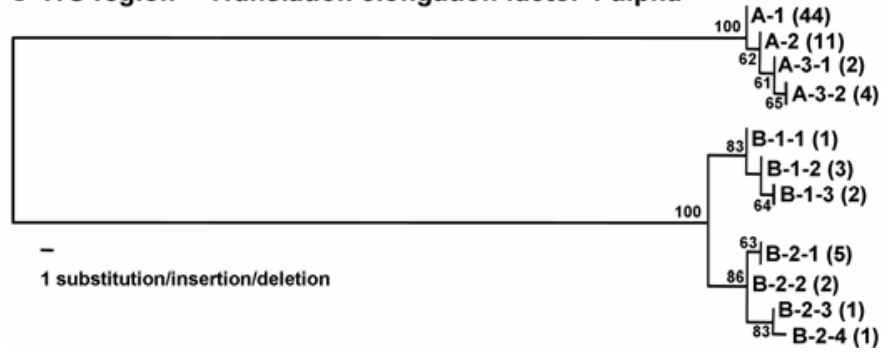

Fig. 3. Phylogenetic tree resulting from maximum parsimony analysis of sequences of the A, internal transcribed spacer region (ITS); $\mathbf{B}$, a fragment of the translation elongation factor $1 \alpha$ (TEF) gene; and $\mathbf{C}$, the ITS and TEF sequences combined for Elsinö̈ spp. causing citrus scab diseases. Bootstrap values are based on 1,000 replicates. There were 11 unique genotypes among isolates when sequences were combined. The position of isolates with these genotypes is indicated in all three trees. The genotypes are identified by the random amplified polymorphic DNA polymerase chain reaction subgroup of isolates having the genotype (Fig. 2) followed by a number if multiple genotypes were present within a subgroup. The number of isolates with each genotype is written in parenthesis and genotype designation for each isolate is listed in Table 1. type was clearly distinguished by pathogenicity tests, RAPDPCR, and the ITS sequence. The A-2 group contained all Tryon's pathotype isolates which came from Australia and New Zealand. It also contained a Lemon pathotype from Australia. Two other Lemon pathotypes, CC-3 from Florida and CC-140 from New Zealand, were not included in this group, suggesting that geographic region rather than pathotype might account for the separation of this group.

We confirmed the presence of the sweet orange pathotype in southern South America as previously reported $(3,7,13,14)$ and confirmed the occurrence of the natsudaidai pathotype in Korea (7) but found no new pathotypes or regions of occurrence for this species. The host range of E. australis has not been thoroughly investigated on fruit. The information on infection of sweet orange fruit in this study was based on previous research $(3,18$, 19). The three isolates from satsuma mandarin in Argentina (70212, Ea-1, and Ea-4) were presumed to be E. fawcettii because they were isolated from satsuma mandarin, a common host of that species. However, all three were found to be E. australis as determined by host range, DNA sequences, and RAPD banding patterns. With specific primers for both species available now (6), determination of the species present on fruit should be more feasible. A preliminary host range of E. australis can be ascertained by molecular means only. However, fruit inoculations will have to be performed to confirm the susceptibility of different species of citrus.

The existence of so many pathotypes of E. fawcettii is perhaps surprising, because the teleomorph of this species occurs rarely and has been found only in Brazil $(2,13,16)$. The sequence data in the present article does not indicate that sexual recombination occurs frequently among major groups identified using molecular methods within E. fawcettii. However, within some groups, recombination might occur at a relatively high frequency which might account for the numerous pathotypes observed within the A-1 group. Citrus originated largely in Southeast Asia, India, and China and, presumably, E. fawcettii originated in that area as well. We presume that citrus scab has been distributed around the world primarily on vegetative propagating material. Different pathotypes appear to predominate in various citrus areas of the world but it appears that many introductions may have occurred in some areas such as Florida and New Zealand with diverse pathotypes with fewer in other areas. However, more extensive sampling would be required in each region to determine the true range of pathotypes that occur in each area. The pathotype range in Australia, for example, may not be well represented because all of the isolates studied were from a lemon-producing area of New South Wales. Additional pathotypes may be discovered if other citrus species are sampled, especially in citrus collections or in residential plantings. There may be local selection for certain pathotypes in some areas based on the citrus cultivars grown.

Sequence analysis of the ITS region and the TEF genes provided strong support for separation of these two species of

TABLE 2. Accession numbers of sequences submitted to the GenBank for 11 genotypes determined from the combined internal transcribed spacer (ITS) region and the transcription elongation factor $1 \alpha$ (TEF) gene observed among Elsinoe spp. and a representative isolate for each genotype

\begin{tabular}{llll}
\hline Genotype & \multicolumn{1}{c}{ ITS } & \multicolumn{1}{c}{ TEF } & \multicolumn{1}{c}{ Isolate } \\
\hline A-1 & FJ010360 & FJ010270 & SM3-1 \\
A-2 & FJ010288 & FJ010212 & 70027 \\
A-3-1 & FJ010323 & FJ010247 & Jin-6 \\
A-3-2 & FJ010320 & FJ010244 & Jin-1 \\
B-1-1 & FJ010328 & FJ010252 & KNa-5 \\
B-1-2 & FJ010326 & FJ010250 & KNa-1 \\
B-1-3 & FJ010336 & FJ010260 & Na-2 \\
B-2-1 & FJ010312 & FJ010236 & Ea-1 \\
B-2-2 & FJ010318 & FJ010242 & FZ-STM-CLB-1.4 \\
B-2-3 & FJ010354 & FJ010284 & VRG-BRT \\
B-2-4 & FJ010291 & FJ010215 & 70212 \\
\hline
\end{tabular}


Elsinoe. RAPD and sequence analysis appears useful to some degree in separating some groups of pathotypes or perhaps the geographical regions of origin of isolates of E. fawcettii. All of the FBHR, FNHR, and SRGC pathotypes grouped closely and were separable from the Tryon's and Lemon pathotypes and from the Jingeul pathotype from Korea. However, as previously mentioned, two Lemon pathotypes, CC-3 and CC-140 from Florida and New Zealand, respectively, grouped with the FBHR, FNHR, and SRGC pathotypes in RAPD analysis. Molecular analyses appear to be useful for preliminary characterization of the possible pathotypes that occur in an area but inoculation of differential host species would be necessary to fully determine the pathotypes present. The natsudaidai and sweet orange pathotypes of E. australis were separable by RAPD and sequence analysis. Specific primers are available to distinguish the two pathotypes of $E$. australis, providing a rapid and specific assay for pathotypes of this species (6), and primers could be designed to distinguish some groups of pathotypes of E. fawcettii.

The results of the present study have some implications for regulatory agencies and for disease control. Because pathotypes of E. fawcettii are somewhat limited in their geographical distribution, restrictions on the movement of plant material may be useful to reduce spread of pathotypes (especially those with a broad host range on commercially important citrus cultivars) to new areas where they do not currently occur. However, movement of vegetative materials into most citrus areas is already prohibited or highly controlled. It is unlikely that scab could spread on commercial fruit because the pathogen is very difficult to isolate from mature fruit directly from the field (L. W. Timmer, unpublished) and blemished fruit is usually eliminated in the packing line for commercial sales. Scab is spread only by splash dispersal and conidia are dispersed only very locally and, thus, most of the spread of any introduced scab pathotype would occur primarily on vegetative propagating material. Knowledge of the predominant pathotype may also have implications for growers who plant certain tangerine and tangerine hybrids as pollenizers for other cultivars. Cultivars that are resistant or tolerant to the principal pathotype in the area should be planted to avoid build-up of inoculum on the pollenizer cultivar.

\section{ACKNOWLEDGMENTS}

We thank M. Priest, New South Wales Agriculture, Orange, NSW, Australia, and S. M. Garran, Instituto Nacional de Técnologia Agropecúaria, Concordia, Entre Rios, Argentina for supplying isolates of Elsinoë spp. from Australia and Argentina; N. A. Peres of the University of Florida, GCREC, Wimauma, FL for the isolates from Brazil; R. A. Fullerton, The Horticulture and Food Research Institute, Auckland, New Zealand for the isolates from New Zealand; and S. N. Mondal for assistance in conducting some of the inoculations in Florida.

\section{LITERATURE CITED}

1. Annamalai, P., Ishii, H., Lalithakumari, D., and Revathi, R. 1995. Polymerase chain reaction and its applications in fungal disease diagnosis. J. Plant Dis. Prot. 102:91-104.

2. Bitancourt, A. A., and Jenkins, A. E. 1936. Elsinoe fawcettii, the perfect stage of citrus scab fungus. Phytopathology 26:393-396.

3. Bitancourt, A. A., and Jenkins, A. E. 1937. Sweet orange scab caused by Elsinoë australis. J. Agric. Res. 54:1-17.

4. Farris, J. S., Källersjö, A., Kluge, G. and Bult, C. 1995. Testing significance of incongruence. Cladistics 10:315-319.

5. Hasegawa, M., Kishino, H., and Yano, T. 1985. Dating the human-ape split by a molecular clock of mitochondrial DNA. J. Mol. Evol. 22:160174.

6. Hyun, J. W., Peres, N. A., Yi, S. Y., Timmer, L. W., Kim, K. S., Kwon, H. M., and Lim, H. C. 2007. Development of PCR assays for the identification of species and pathotypes of Elsinoë causing scab on citrus. Plant Dis. 91:865-870

7. Hyun, J.-W., Timmer, L. W., Lee, S.-C., Yun, S.-H., Ko, S.-W., and Kim, K.-S. 2001. Pathological characterization and molecular analysis of Elsinoë isolates causing scab diseases of citrus in Jeju Island in Korea. Plant Dis. 85:1013-1017.

8. Jenkins, A. E. 1936. Australian citrus scab caused by Sphaceloma fawcettii scabiosa. Phytopathology 26:195-197.

9. Larkin, M. A., Blackshields, G., Brown, N. P., Chenna, R., McGettigan, P. A., McWilliam, H., Valentin, F., Wallace, I. M., Wilm, A., Lopez, R., Thompson, J. D., Gibson, T. J., and Higgins, D. G. 2007. Clustal W and Clustal X version 2.0. Bioinformatics 23:2947-2948.

10. Nelson, R. J., Baraoidan, M. R., Vera Cruz, C. M., Yap, I. V., Leach, J. E., Mew, T. W., and Leung, H. 1994. Relationships between phylogeny and pathotype for the bacterial blight pathogen of rice. Appl. Environ. Microbiol. 60:3275-3283.

11. Posada, D., and Crandall, K. A. 1998. MODELTEST: Testing the model of DNA substitution. Bioinformatics 14:817-818.

12. Rohlf, F. J. 1998. NTSYS-pc, Numerical Taxonomy and Multivariate Analysis System, version 2.0. Department of Ecology and Evolution, State University of New York, Stony Brook.

13. Sivanesan, A., and Critchett, C. 1974. Elsinoë australis. CMI Descriptions of Pathogenic Fungi and Bacteria No. 440. CAB International, Wallingford, UK.

14. Sivanesan, A., and Critchett, C. 1974. Elsinoë fawcettii. CMI Descriptions of Pathogenic Fungi and Bacteria No. 438. CAB International, Wallingford, UK.

15. Sivanesan, A., and Critchett, C. 1974. Sphaceloma fawcettii var. scabiosa. CMI Descriptions of Pathogenic Fungi and Bacteria No. 437. CAB International, Wallingford, UK.

16. Tan, M. K., Timmer, L. W., Broadbent, P., Priest, M., and Cain, P. 1996. Differentiation by molecular analysis of Elsinoë spp. causing scab diseases of citrus and its epidemiological implications. Phytopathology 86:1039-1044.

17. Timmer, L. W., Priest, M., Broadbent, P., and Tan, M.-K. 1996. Morphological and pathological characterization of species of Elsinoë causing scab diseases of citrus. Phytopathology 86:1032-1038.

18. Whiteside, J. O. 1978. Pathogenicity of two biotypes of Elsinoë fawcettii to sweet orange and some other citrus cultivars. Phytopathology 68:11281131.

19. Whiteside, J. O. 1984. Infection of sweet orange fruit in Florida by a common biotype of Elsinoë fawcettii. Proc. Int. Soc. Citricult. 2:343-346. 